\title{
Path Analysis of College Students' Party Building Work under the New Media Environment
}

Haitao $\mathrm{Li}^{1, \mathrm{a}}$

${ }^{1}$ College of Information and Control Engineering, Jilin Institute of Chemical Technology, Jilin City, Jilin Province,

$$
\begin{gathered}
\text { 132022, China } \\
\text { a466137114@qq.com }
\end{gathered}
$$

Keywords: New media; College students; Party building work; Path analysis

Abstract. Nowadays, the new media is developing rapidly. The combination of the new media and college students' Party building work will help to improve students' Party building work level and cultivate qualified talents. This paper expounds the development status of college students' Party building work under the new media environment, the importance of college students' Party building from the perspective of new media, the advantages of integrating new media into college students' Party building work, and how to do the Party building work well under the new media environment.

\section{新媒体环境下大学生党建工作路径探析}

\section{李海涛}

摘要: 现如今, 新媒体发展迅速, 将新媒体与大学生党建工作巧妙地结合起来, 有利于提高学生党建工作水平, 培养出 合格的人才。本文从新媒体环境下大学生党建工作的发展现状、在新媒体视阈下对大学生党建的重要性、新媒体融入大学生 党建工作的优势以及如何做好新媒体环境下的党建工作来进行阐述。

关键词：新媒体；大学生；党建工作；路径探析

引言

新媒体作为一种具有全新物质形态和时空观念的媒体，以互联网、无线通信网等为媒介来为大众提供 信息，促进传播者和接受者间的交流，并在这一过程中呈现出表现形式多样性、发布信息及时性等特点。 目前, 新媒体已经在大学生中得到广泛普及, 在信息的搜集、彼此的交流与联络方面发挥着关键作用。而 大学生党建工作在思政工作中起着关键作用, 新时期的大学生党建工作应与时俱进, 提高党建工作效能。 让新媒体最大限度的发挥其作用，为党建工作注入活力，提高党建工作效能。

\section{1 新媒体环境下大学生党建工作的发展现状}

正如范鸿飞在《新媒体环境下高校党建工作的现状及对策》中指出的目前 “高校党建工作方式方法滞 后于新媒体技术的迅猛发展, 党建工作成效受制于新媒体海量信息的监管难度以及高校党建工作人员运用 新媒体技术的水平能力有待提高”。

理论研究与实际工作结合不紧密, 如今, 高校学生党建工作没有与新媒体技术紧紧地联系在一起, 高 校学生党建工作人员对新媒体技术的重视程度不够, 大多数高校学生党建工作者还不太习惯在工作时使用 新媒体网络技术。传统党建教育模式已不能够新时期党建工作的需要, 部分高校的教育观念和教育体制亟 待提高。高校党建工作者对于新媒体网络技术在大学生党建过程中的运用没有深刻的认识, 仅看到了新媒 体对于党建工作存在的弊端, 再加上部分高校党建人员的专业程度不够, 年龄较大, 导致他们在开展工作 
的过程中对新媒体的操作不够熟练, 不能根据实际情况去解决问题。而新媒体的开放也出现了思潮多元交 错的现象, 新媒体作为一个信息库, 里面包含着大量而复杂的信息。这就要求受众应具备较高的信息识别能 力。新媒体环境下, 有的高校党建工作的统筹力度不到位, 从事党务工作的人员中, 辅导员人数居多, 由 于其平时事务较多, 不能将更多的时间和精力投入到党建工作中, 除此之外, 部分高校并未建立健全党建 工作管理机制, 保障力不到位。再加上部分学生党员缺乏理论素养, 入党后放松了对自己的要求, 政治觉 悟较低。

\section{2 在新媒体视阈下对大学生党建的重要性}

第一, 新媒体技术是巩固高校大学生党建宣传阵地的迫切需要。随着新媒体技术被逐渐应用到生活中, 成为了新媒体环境下高校大学生党建工作的主要宣传阵地。这就需要广大的高校大学生党组织工作者不断 地去完善自己, 合理的运用新媒体技术做好党建宣传工作, 营造出一个良好的氛围, 从而更好去引领、武 装和团结大学生党员。

第二，充分利用新媒体技术是推动高校大学生党建工作民主建设的需要。在新媒体环境下，人人都享 有自由平等的话语权。在这种环境下, 一些处于被动地位的党员群体享有更多的民主参与权, 充分调动大 学生党员的积极性, 使党内事务的管理工作开展的更加顺利。

第三，运用新媒体技术是当前高校大学生党员群体的必然选择。当下处于信息时代，人们的生活方式 被互联网的信息技术和通信技术潜移默化的影响着。利用新媒体开展大学生党建工作顺应了二十一世纪信 息时代的要求, 对于党的生产力起促进作用。我国高校大学生群体大多为能够熟练运用新媒体工具的 “ 00 后”, 他们接受能力强, 更倾向于把新媒体作为与外界交流的平台。因此, 将新媒体引入高校大学生党建 工作管理中，符合当前高校大学生党员群体的需求。

\section{3 新媒体融入大学生党建工作的优势}

第一，互动性强。新媒体环境下，高校党建工作者和受众之间的互动变得更加频繁，使党员之间的交 流变得更加亲切, 有益于提高学习效率, 构建高校学生党建立体、多元化工作模式, 打破之前传统的教育 方式, 使大学生党员拥有自我学习的主动性。

第二, 具有更迅速、广泛的传播性。传统高校大学生党员教育受文化课上课时间、地点等因素的限制, 主要以课堂授课、会议讨论等形式为主。在新媒体环境下, 可以利用手机、电脑等各种多媒体及时的更新 和发布党员教育信息, 不必考虑哪一时间, 哪一地点, 这样做, 高校大学生教育途径将变得更加方便省时。

第三, 新媒体具有更广泛的影响力。传统的党建设教育主要通过文字、课本等方式来把内容呈现出来, 而新时期的党建设教育则有更多新的途径, 可将信息通过手机、电脑及一些社交软件呈现出来, 而受众也 可以在任一时间任何地点获取对自己有价值的信息。新媒体的便捷性极大程度地提高了党员教育内容的传 播效率, 因此, 它对人们的影响更为广泛。

\section{4 新媒体下大学生党建工作的创新路径}

\section{1 应遵循的原则}

\section{1 .1 系统性原则。}

大学生党建工作应根据基层党建的基本要求来开展, 并在逐步完善的过程中体现出系统性原则, 着力 
提升学生党员的素质, 积极组织具有鲜明特点的各项活动。

\section{1 .2 导向性原则。}

大学生党建工作应是全面的、具体的, 将各项内容如办学的指导思想, 基层党建的目标等都融合在一 起, 培养出拥有正确三观即人生观、世界观、价值观, 对社会主义核心价值观有着深刻理解, 能够严格要 求自己的合格党员。

\section{1 .3 创新性原则。}

当前 “00 后” 的大学生们, 求知欲强, 对于新鲜的事物充满好奇心, 这就意味着这就意味着大学生党 建工作要与时俱进, 既要继承, 又要发展创新, 并根据现阶段学生的特点来制定出切实可行的计划, 建立 健全党建机制。

\section{2 新媒体下创新学生党建工作的措施}

\section{2. 1. 加强思想政治教育, 创新学生党建活动载体。}

思想政治工作是党工作的重心，因此，加强大学生的思想政治教育是大学生党建工作中的重要一环。 在班级里成立 “党小组”, 在年级里成立 “党支部”, 让学生党员对自身严格要求, 为普通同学树立榜样, 激励普通同学向优秀的学生党员学习, 增强对党的了解和认识, 充分体现出党支部是一个可以将年级力量 凝聚在一起的组织。同时, 把微博、微信等新媒体技术作为有力平台, 把党的基本理论知识、方针路线、 纲领使命等列为主要的学习内容, 积极开拓 “网络理论学习阵地”, 充分发挥新媒体的即时性优势, 开辟 网上互动专区, 挑选出一些对于理论知识掌握透彻的党务工作者对大学生提出的问题予以及时细致的回 答, 以便于增进与大学生之间的交流。

\section{2 .2 加强作风制度建设, 扩大民主生活会的影响力。}

学生党支部要邀请优秀的教师党员、学生党员、预备党员参加民主生活会。对学生党员、预备党员提 出明确要求, 对自己近期的学习、工作、生活等情况进行概括总结, 对表现优秀者予以表彰, 使其不断向 前, 力争成为优秀党员。同时, 加大对入党积极分子的考察力度, 让其在良性的竞争中不断提升自身素质, 努力发展成为正式党员。在学生党建网站上及时地对各项制度进行及时公示, 扩大民主生活会影响力, 让 学生党员在不知不觉中将主流价值观、社会准则牢记于心，逐渐成为合格党员。

\section{2.3 推进党建网络與情工作, 发挥主流文化的引导力。}

党建网络舆情可以反映出大学生党员的心中所想及所要提的意见。在新媒体环境下, 高校基层党务工 作者应保持对网络信息的敏感度, 加大党建网络與情工作力度, 努力营造出良好的学习氛围。

首先，要利用新技术打造出一个网站，并将此网站能否带来强大的视觉冲击力、内容是否充实等相关 因素考虑在内。对于一些关注度较高的校园新媒体平台如校党委官方微博、微信等进行精心策划, 一方面 用于发布重要信息通知, 另一方面用于师生间的互动, 使校园新媒体平台成为主要的学习阵地。

其次, 组建一支强有力的校园與情监控队伍。新媒体是一个巨大的信息库, 在给人们带来便利的同时, 也有其不足之处, 比如其信息的可信度令人怀疑。因此, 监控校园舆情有着不了替代的作用, 这需要学生、 教师等相关职能部门的配合, 引导校园與论风向。这支队伍应积极传递正能量, 寻找放大能够体现教育时 政价值的事件, 以引起大众的广泛关注; 及时的对一些错误的、不准确的信息进行修正和更改, 这有利于 建设良好的校园教育环境, 使思政教育更具有说服力和吸引力。最后, 培养出学生 “意见领袖” , 引导校 
园與论风向, 提升网络主流文化影响力, 净化校园與情环境。所谓意见领袖即为在网络传播中能够对他人 产生影响的 “活跃分子”。他们可以将信息扩散给受众, 在大众传播效果的形成过程中起着中介或过滤作 用, 用以形成信息传递的两级传播。而着力在学生群体中培养出 “意见领袖” , 则更有利于监管好校园與 情环境。

\section{5 坚持与时俱进, 提高基层党务工作者媒介素养}

媒介素养是能够体现媒介信息的意义和独立判断信息价值的知识结构，是一种对媒介信息的选择、理 解等的应变能力。在这个科技迅速发展的时代, 高校基层党务工作者提高自身素养刻不容缓, 应尽快掌握 新媒体技术的使用方法，并能够熟练的应用到实际问题中，努力提高育人成效，同时通过新媒体技术，对 先进文化知识进行大力宣传, 让学生尽早了解到这些文化知识的内涵, 扩大教育影响力; 通过微博、微信、 $\mathrm{QQ}$ 等网络平台发表个人对于一些事件的看法, 引导学生积极健康的成长, 提高思想政治教育实效性。

在信息化背景下, 我们需充分认识到新媒体在高校学生党建工作中的重要性, 并把新媒体合理的引入 到高校学生党建工作中。想要拓展和丰富高校学生党建工作内容, 需要借助以网络为主的媒体, 深刻地了 解新媒体的传播优势及特点, 并且及时的纠正大学生党建工作存在的问题, 在先进媒体技术和理念的支持 下，使高校学生党建工作的质量和水平得到显著地提升。

\section{作者简介：}

李海涛，男，汉族，吉林化工学院副教授，研究方向为法学、马克思主义中国化。（ 吉林 132022）

\section{参考文献:}

[1] 洪福兴．新媒体视阈下高校学生党建工作创新研究 $[J]$ ．湖北经济学院学报（人文社会科学版） [J]．2016（9）

[2] 史伟. 高校学生党建如何更 “接地气” $[J]$ ．人民论坛．2017（2）

[3] 再永琴．新媒体下高校基层学生党建创新路径研究 $[\mathrm{J}$ ．重庆工商大学日报．2016（10）

[4] 万里勇．新媒体背景下高校大学生党建工作创新路径研究 [J]．2016（4）

[5] 关江宏、梁广东、刘姬冰．新媒体视域下大学生党建工作创新路径探析 $[J]$. 绥化学院农业与水利工程学院. 2016 (8)

[6]喻瑜. 新媒体时代高校学生党建工作创新研究 [J]．2016（6）

\section{Reference}

[1] F.X.Hong: Research on the Innovation of College Students' Party Building from the Perspective of New Media[J], Journal of Hubei University of Economics(Humanities and Social Sciences), 2016(9).(In Chinese)

[2] W.Shi: How to Make the College Students' Party Building "Down to Earth"[J], People's Tribune, 2017(2).(In Chinese)

[3] .Q.Ran: Research on the Path of the Innovation of Party Building of Basic-level Students in Colleges under the New Media[J], Chongqing Technology and Business University Daily, 2016(10). (In Chinese)

[4] L.Y.Wan: Research on the Path of the Innovation of College Students' Party Building under the New Media[J], Journal of News Research, 2016(4).(In Chinese)

[5] J.H.Guan, G.D.Liang and J.B.Liu: Analysis of the Path of the Innovation of College Students' Party Building under the New Media[J], Journal of Suihua University, 2016(8).(In Chinese)

[6] Y.Yu: Research on the Innovation of College Students' Party Building Work in the New Media Era[J], 2016(6).(In Chinese) 